\title{
Land-Use Suitability in Northeast Iran: Application of AHP-GIS Hybrid Model
}

\author{
Elnaz Memarbashi ${ }^{1}$, Hossein Azadi ${ }^{2,3, *}$, Ali Akbar Barati ${ }^{4}$ (D), Fatemeh Mohajeri ${ }^{1}$, \\ Steven Van Passel ${ }^{5,6}$ and Frank Witlox 2,7,8 \\ 1 Department of Agroecology, Faculty of Agriculture, Azad University of Mashhad, 9187864584 Mashhad, \\ Iran; nazi_memarbashi@yahoo.com (E.M.); f.mohajeri37@gmail.com (F.M.) \\ 2 Department of Geography, Ghent University, B-9000 Ghent, Belgium; frank.witlox@ugent.be \\ 3 Economics and Rural Development, Gembloux Agro-Bio Tech, University of Liege, B-4000 Liege, Belgium \\ 4 College of Agriculture and Natural Resources, Faculty of Agricultural Economics and Development, \\ Department of Agricultural Management and Development, University of Tehran, 1417466191 Tehran, Iran; \\ aabarati@ut.ac.ir \\ 5 Faculty of Applied Economics, Department of Engineering Management, University of Antwerp, \\ Prinsstraat 13, B-2000 Antwerp, Belgium; steven.vanpassel@uantwerpen.be \\ 6 Centre for Environmental Sciences, Hasselt University, Martelarenlaan 42, B-3500 Hasselt, Belgium \\ 7 College of Civil Aviation, Nanjing University of Aeronautics and Astronautics (NUAA), \\ Nanjing 210016, China \\ 8 Department of Geography, University of Tartu, 21014 Tartu, Estonia \\ * Correspondence: hossein.azadi@ugent.be; Tel.: +32-(0)9-264-4695; Fax: +32-(0)9-264-4985
}

Received: 5 October 2017; Accepted: 22 November 2017; Published: 1 December 2017

\begin{abstract}
Land-use suitability is the ability of a given type of land to support a defined use. Analysis of land-use suitability requires the consideration of a variety of criteria, not only the natural/physical capacity of a land unit, but also its socioeconomic and environmental impact implications. As land suitability is assessed within a Geographic Information System (GIS) environment, it is formulated as a multi-criteria decision making (MCDM) problem. The study was conducted in the Sangab Plain in northeast Iran. We investigated the study area's suitability for grassland and agricultural uses. A hybrid method of the analytic hierarchy process (AHP) and GIS methodology was applied to evaluate land suitability based on a set of criteria and sub-criteria. Results showed that $20 \%$ of the study area had high (rich), $65 \%$ had medium (fair), and $15 \%$ had low (poor) suitability for agriculture. In terms of grassland use, the comparable amounts were, respectively, about $7 \%, 23 \%$, and $70 \%$. The lands of the Sangab Plain have medium potential for agricultural use and low potential for grassland use. This paper used both qualitative and quantitative techniques.
\end{abstract}

Keywords: land suitability; AHP-GIS hybrid method; agricultural land uses; grassland uses; Sangab Plain

\section{Introduction}

Land as a part of the earth's surface has reasonably stable or predictable cyclic activity. Its suitability for agriculture, settlement and industry [1] depends on its elements. However, these elements have been depleted, especially in the last few centuries. As a result, many lands are facing problems such as soil erosion, water logging, groundwater depletion, heavy run-off and productivity losses [2,3] which are threatening the quality and availability of food, water and energy, and are affecting the security and quality of life of 250 million people and compromising the lives of one billion [4]. For example, FAO has reported that 852 million people in the developing world are suffering from hunger and malnutrition [5]. In addition, land resources are becoming scarce as an 
increasing population puts pressure on natural resources. As the world population grows, a greater food supply is urgently needed. Additionally, the land use policies in developing countries frequently makes little use of the available technical information and when they do, policy makers require it to be interpreted into brief statements that eliminate technical details [6]. Land suitability assessment is similar to choosing a location for land use and aims to map a suitability index for the entire study area [7]. Selecting the most appropriate algorithm for land suitability assessment is important for current and future land use planning [8]. The creation of suitability maps is one of the most important prerequisites for land-use decisions. Many parameters and criteria on land and its uses must be considered. Social and economic factors are often more manipulated by human interventions than are bio-physical and environmental factors [8]. Thus, determining the weight of each factor that affects land suitability is a key step in land suitability assessment for crop production [9]. Since each factor has its own level of importance or weight for the interest groups involved, weighting them can be difficult. Multi-criteria techniques can be used to solve this complex and multi-dimensional problem. A variety of multi-criteria evaluation methods is available [10]. McHarg and Mumford [11] introduced a planning method of systematic land use by applying the concept of compatibility among multiple land uses. He mentioned that the factors affecting land and its relative value vary, so it is difficult to optimize them for a specific single use. However, it can be optimized for multiple, compatible uses so he introduced a simple matrix system to determine the degree of compatibility. In recent years, the combination use of multi-criteria decision making (MCDM) and Geographical Information Systems has been expanded. This combination has improved the processes of land evaluation, decision-making and the efficiency of data processing [12-14]. The analytic hierarchy process (AHP) is best illustrated by Saaty [15], who described it as a decision support tool that can be used to solve complex decision problems. This process uses a multi-level hierarchical structure of objectives, criteria, sub-criteria, and other alternatives. Interest in multi-criteria assessment in agriculture, environmental and rural studies and management has been growing rapidly due to the possibilities it can present [16-21]. Moreover, it can help improve the description of land utilization types that are required for land evaluation [12-23] and provide a powerful spatial decision support system that enables researchers to produce accurate land suitability maps. The combination of AHP with GIS is a new trend in land suitability analysis [14] as previous studies have combined and applied multi-criteria decision making (MCDM) techniques, especially AHP, based on GIS. For example, Gemitzi, Tsihrintzis, and Petalas [24] used these two techniques to integrate the evaluation of environmental problems. Krois and Schulte [25] combined the two evaluation techniques to identify potential sites for soil and water conservation techniques in the Ronquilo watershed, Northern Peru. Al-Adamat, Diabat, and Shatnawi [26] used the combination of the GIS with MCDM to site water harvesting ponds in Northern Jordan; Zhang et al. [8] integrated the fuzzy set model, analytic hierarchy process (AHP) method, and GIS technique to assess land suitability and to create a land suitability map for tobacco production in the tobacco zone of Shandong province, China. They used 20 factors as suitability parameters, including climatic condition, soil type and nutrient characters, and topographical data. Some studies [27-29] have also used multi-criteria and GIS-based methods to analyze the suitability of land for other uses such as waste disposal and management. Ekmekçioĝlu et al. [27] proposed a modified fuzzy TOPSIS methodology for the selection of an appropriate disposal method and site for municipal solid waste (MSW). According to them, the application of fuzzy multiple criteria analysis (MCA) in solid waste management has the advantage of rendering subjective and implicit decision making more objective and analytical, and accommodates both quantitative and qualitative data. Baiocchi et al. [28] used three decision support methods (Boolean logic, index overlay and fuzzy gamma) to perform land suitability analysis for landfill siting. Tavares et al. [29] presented a spatial multi-criteria evaluation methodology to assess land suitability for a plant siting and applied it to Santiago Island of Cape Verde. This study's analysis of land-use suitability focuses on the potential for agricultural and grassland land uses in the Sangab Plain, northeast of the Khorasan-Razavi province (Figure 1). The Sangab Plain has a semi-desert climate, with cold winters and warm and dry summers, with the areas of dry and low rainfall that 
are components of plains. The people there depend on agriculture, livestock and mining with water from by rivers and from aqueducts. The most important agricultural products of the plain include wheat, barley, corn, and products from orchards. Livestock and poultry are common in the industrial and traditional areas of this plain. The AHP method that was used to evaluate the land has consists of specifying the hierarchical structure, determining the relative importance of criteria and sub-criteria, assigning the preferred weights of each alternative, and calculating the final score [30]. A GIS was then used to calculate soil and the three varying terrains: slopes, elevation, and aspect.

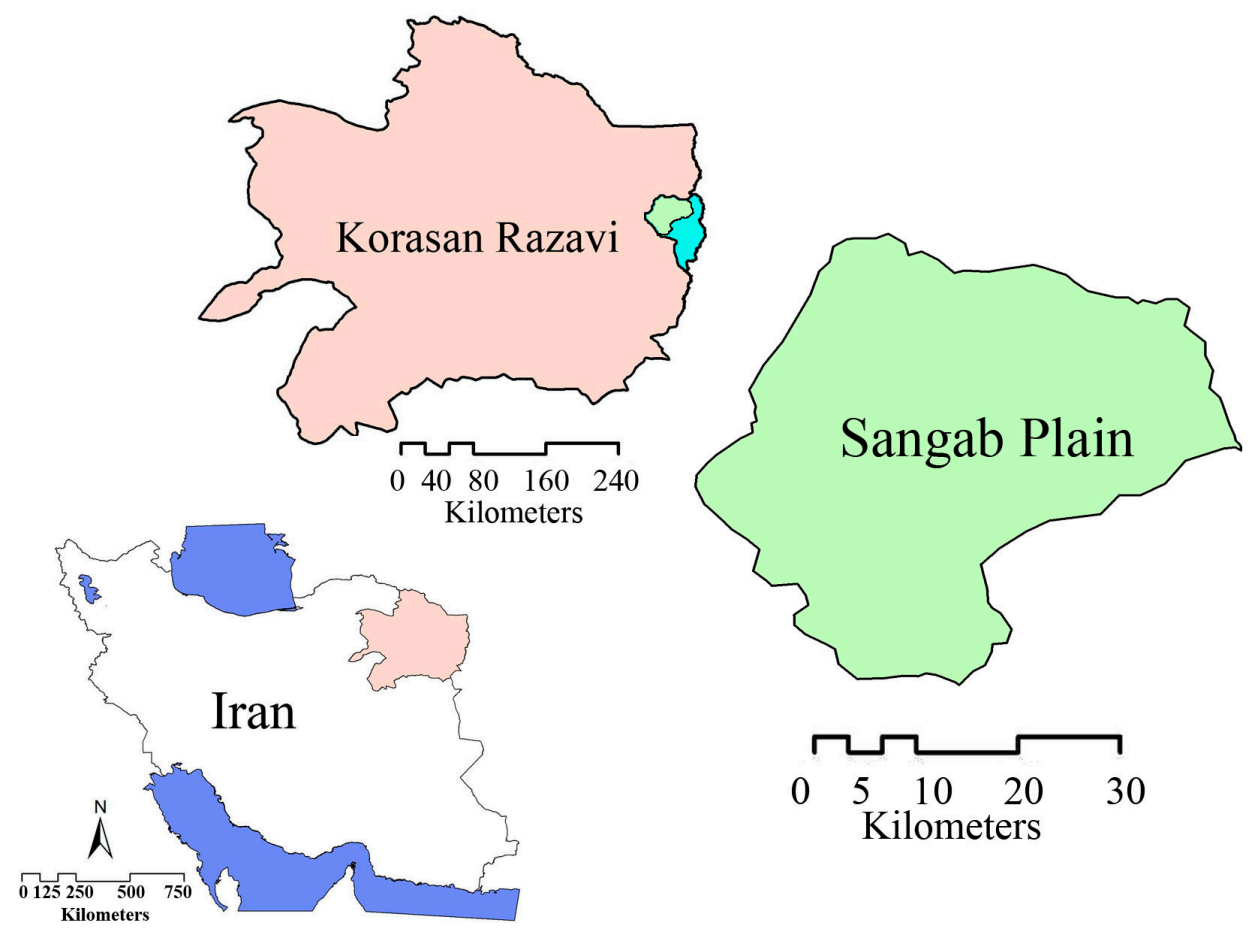

Figure 1. The study site.

\section{Methodology}

\subsection{Data}

The data used in this research has bio-physical and socio-economic aspects. The primary data were collected from the field survey through interviews and questionnaires. The questionnaires were filled out by experts to identify factors that are important for evaluating land-use suitability along with statistical data and other GIS datasets. Land and topographic data-slope, slope aspect, elevation, soils, and land use-were taken from the Iranian topographic map at a scale of 1:25,000, produced by Iran National Cartographic Center (INCC).

\subsection{Analytic Hierarchy Process (AHP)}

AHP was used to weigh the criteria and sub-criteria. It can accurately evaluate land suitability. This method begins by using a hierarchy depicting the criteria, sub-criteria, and decision alternatives (Figure 2), with the goal or mission of the decision-making problem placed at the top. Other criteria and sub-criteria were placed in the remaining levels [31]. The second stage involved the comparison of pairs of criteria, pairs of sub-criteria and pairs of alternatives. The AHP uses a 9-point scale measurement ( 1 = equal importance, $3=$ moderate importance of one over another, $5=$ strong or essential importance, $7=$ very strong or demonstrated importance, $9=$ extreme importance, and 2, 4, 6, $8=$ intermediate values) to express individual preferences or judgments [15]. 


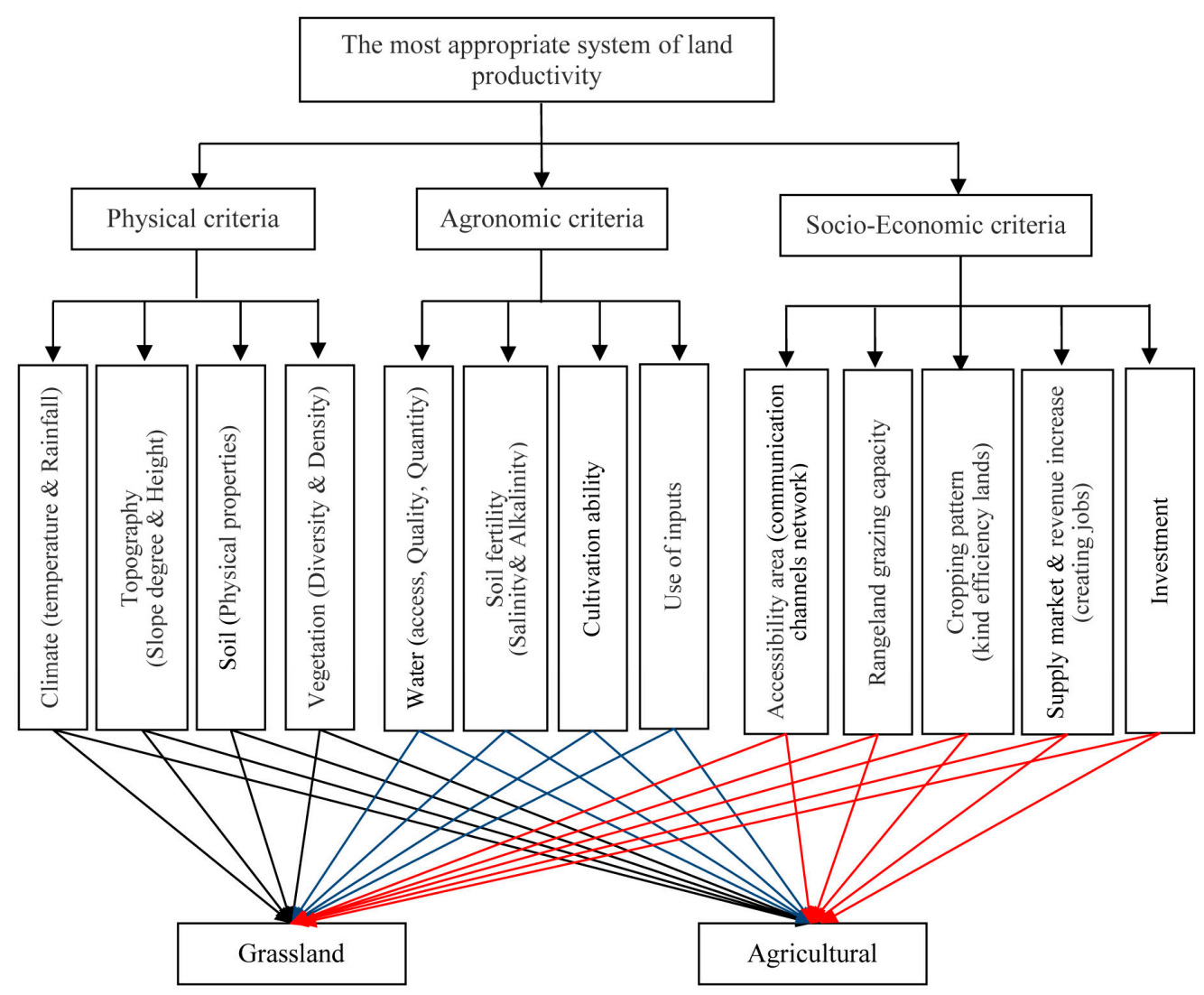

Figure 2. The flowchart of AHP land-use suitability assessment.

\subsection{Geographic Information System (GIS)}

The weighted sum overlay analysis in the ArcGIS software was used to map the suitability of land. The estimated weights were appointed to the related layers and then the raster maps were overlaid and an agricultural land suitability map was generated [32]. Four steps were followed to produce a site suitability map: (1) finding suitable factors to use in the analysis, (2) assigning factor priority (weight) to the parameters, (3) generating a land suitability map of agriculture and grasslands, and (4) determining the suitability evaluation of the areas [33].

Five important geographical layers were incorporated (slope, slope aspect, elevation, soils, and land use). Data from all of the selected factors were kept, displayed, and managed. These geographical maps were overlaid to create the final suitability classification of the study area for agriculture and grassland. The weighted sum overlay analysis can be performed with ArcGIS software. Finally, to determine the land suitability index, the following formula was used [32,34]:

$$
L S \sum_{i=1}^{n} w_{i} s_{i}
$$

where $L S$ is land suitability; $w_{i}$ is weight of land suitability criteria; $s_{i}$ is the score of criteria $i$; and $n$ is the number of land suitability classes.

\subsection{Ecological Models}

To survey the situation and the potential of the environmental area and evaluate the land suitability of the study area for agriculture and grassland two models were provided. These models contain Makhdum's [35] ecological model of grassland and agricultural usage, which consists of irrigated cultivation, rain-fed cultivation, working faced, horticulture, animal husbandry, apiculture, 
beekeeping and grassland uses, which pertains to business sheep fields, dynamic cattle, and wildlife grazing. These models are based on for criteria: current use, height, soil type, slope and floor.

\section{Results}

\subsection{AHP Weights}

To determine the preferences of the two elements of the hierarchy in the constraints matrix, a 9-point underlying semantic scale was used. The sum of each column within the matrix was normalized and weights are calculated. Numerical values were assigned to each pair of constraints by using the guidelines (Tables 1-4).

Throughout analysis/decision support/weight, the weights were developed by providing a series of pairwise comparisons of the importance of factors to the suitability of pixels from the activity being evaluated. In fact, a major challenge was the derivation of the weights in light of the decision objective.

Table 1. Paired comparison of first layer criteria in suitability evaluation of the Sangab Plain.

\begin{tabular}{ccccc}
\hline Criteria & (P) & (A) & (E) & Weight \\
\hline Physical criteria (P) & 1 & 4 & 5 & 0.674 \\
Agronomic criteria (A) & 0.25 & 1 & 3 & 0.226 \\
Socio-economic criteria (E) & 0.20 & 0.33 & 1 & 0.101 \\
Consistency ratio & & & & 0.076 \\
\hline
\end{tabular}

Table 2. Paired comparison of sub-criteria, physical criteria in suitability evaluation of the Sangab Plain.

\begin{tabular}{cccccc}
\hline Sub-Criteria & $\mathbf{( P 1 )}$ & $\mathbf{( P 2 )}$ & $\mathbf{( P 3 )}$ & $\mathbf{( P 4 )}$ & Weight \\
\hline Climate (P1) & 1 & 4 & 7 & 8 & 0.611 \\
Topography (P2) & 0.25 & 1 & 5 & 6 & 0.261 \\
Soil (P3) & 0.14 & 0.20 & 1 & 2 & 0.077 \\
Vegetation (P4) & 0.13 & 0.17 & 0.50 & 1 & 0.05 \\
Consistency ratio & & & & & 0.068 \\
\hline
\end{tabular}

Table 3. Paired comparison of sub-criteria, agronomic criteria in suitability evaluation of the Sangab Plain.

\begin{tabular}{cccccc}
\hline Sub-Criteria & (A1) & (A2) & (A3) & (A4) & Weight \\
\hline Water availability (A1) & 1 & 4 & 7 & 8 & 0.611 \\
Soil fertility (A2) & 0.25 & 1 & 5 & 6 & 0.261 \\
Cultivation ability (A3) & 0.14 & 0.2 & 1 & 2 & 0.077 \\
Use of inputs (A4) & 0.13 & 0.17 & 0.5 & 1 & 0.05 \\
Consistency ratio & & & & & 0.068 \\
\hline
\end{tabular}

Table 4. Paired comparison of sub-criteria, socioeconomic criteria in suitability evaluation of the Sangab Plain.

\begin{tabular}{ccccccc}
\hline Sub-Criteria & (E1) & (E2) & (E3) & (E4) & (E5) & Weight \\
\hline Accessibility area (E1) & 1 & 3 & 5 & 6 & 8 & 0.496 \\
Rangeland grazing capacity (E2) & 0.33 & 1 & 4 & 5 & 7 & 0.287 \\
Cropping pattern (E3) & 0.2 & 0.25 & 1 & 2 & 4 & 0.111 \\
Supply market and revenue increase (E4) & 0.17 & 0.2 & 0.5 & 1 & 2 & 0.067 \\
Investment (E5) & 0.13 & 0.14 & 0.25 & 0.5 & 1 & 0.039 \\
Consistency ratio & & & & & & 0.044 \\
\hline
\end{tabular}

When considering lands for future development, much of the suitability depends on developing different abilities and road accessibility. The study area has is reasonably good road accessibility, with all lands not more than $500 \mathrm{~m}$ away from a major or a minor road. As a result, when lands are buffered, 
it always falls outside the area. This indicates that road access is not a constraint in determining developable suitability (Table 4).

Table 5 indicates the partial and overall weight of each criteria and sub-criteria. According to this table, the most important criteria that determines the suitability of land had been physical criteria (0.674). This criterion was respectively, about three and six times more important than agronomic and economic — social criteria. In addition, based on the column "partial weight" within the physical, agronomic and socio-economic criteria, respectively, climate (0.611), water availability (0.611) and accessibility area (0.496) were the most important sub-criteria. However, as the "overall weight" column shows, climate (0.412), topography $(0.176)$, and water availability $(0.138)$ were the key sub-criteria for determining the land suitability.

Table 5. The partial and overall priorities (weights) of criteria and sub-criteria.

\begin{tabular}{|c|c|c|c|c|}
\hline Criteria & Weight of Criteria & Sub-Criteria & Partial Weight & Overall Weight \\
\hline \multirow{2}{*}{ Physical criteria (P) } & \multirow{2}{*}{0.674} & Topography (P2) & 0.261 & 0.176 \\
\hline & & Vegetation (P4) & 0.05 & 0.034 \\
\hline \multirow{2}{*}{$\begin{array}{l}\text { Agronomic } \\
\text { criteria (A) }\end{array}$} & \multirow{2}{*}{0.226} & Water availability (A1) & 0.611 & 0.138 \\
\hline & & Soil fertility (A2) & 0.261 & 0.059 \\
\hline \multirow{5}{*}{$\begin{array}{l}\text { Socio-Economic } \\
\text { criteria }(\mathrm{E})\end{array}$} & \multirow{5}{*}{0.101} & Accessibility area (E1) & 0.496 & 0.050 \\
\hline & & Rangeland grazing capacity (E2) & 0.287 & 0.029 \\
\hline & & Cropping pattern (E3) & 0.111 & 0.011 \\
\hline & & Supply market and revenue increase (E4) & 0.067 & 0.007 \\
\hline & & Investment (E5) & 0.039 & 0.004 \\
\hline
\end{tabular}

Figure 3 compares the consistency of the criteria and sub-criteria. Socio-economic sub-criteria had the lowest consistency rate of all criteria and sub-criteria. This means that the experts agreed with each other more on this criterion than on the others. Furthermore, the experts disagreed the most about socio-economic criteria.

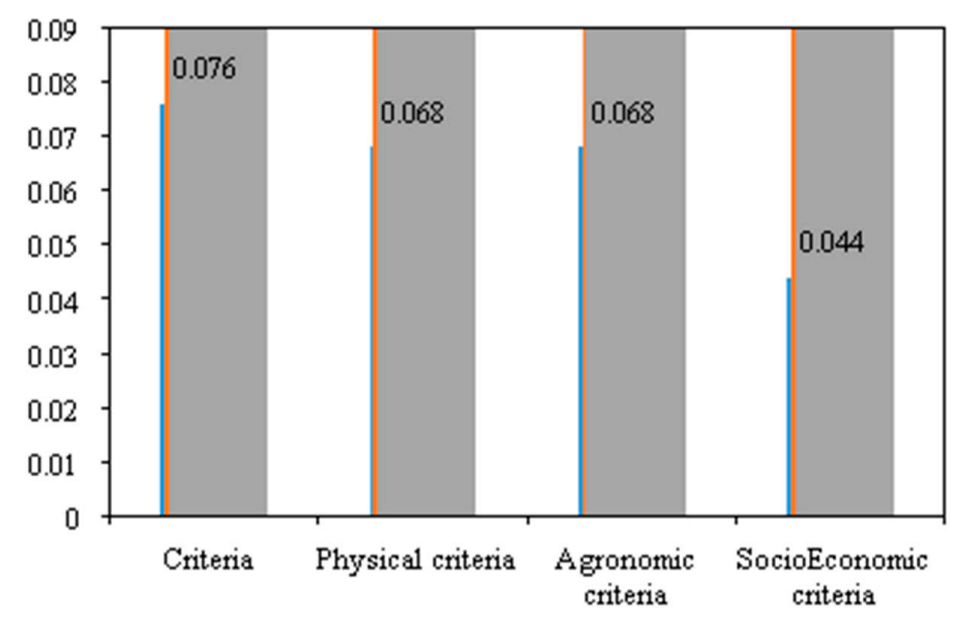

Figure 3. CR comparison for evaluation of ecological potentiality of the Sangab Plain.

\subsection{Spatial Analyses}

After calculating the results of the hierarchical formation, spatial analyses form the basis of the area's slope, elevation, slope aspects, soil map, and the study area's current land uses. All of these were the same as the agriculture and grassland potential evaluation indexes of the area and are presented in the form of digital maps that are used in the evaluation process (Figures 4-8). 


\subsubsection{Slope}

Soil formation is closely related to geomorphologic properties. Slope degree is the main determinant of erosion control [36]. The slope percent map of the Sangab Plain has five levels; the lowest slope in this area is between 0-2 and the highest is $30-90 \mathrm{~m}$. Low slope areas present flat lands and high slope areas show mountain areas. Figure 4 shows that the northern and southern parts of this area have a steeper slope than the east and center of this plain.

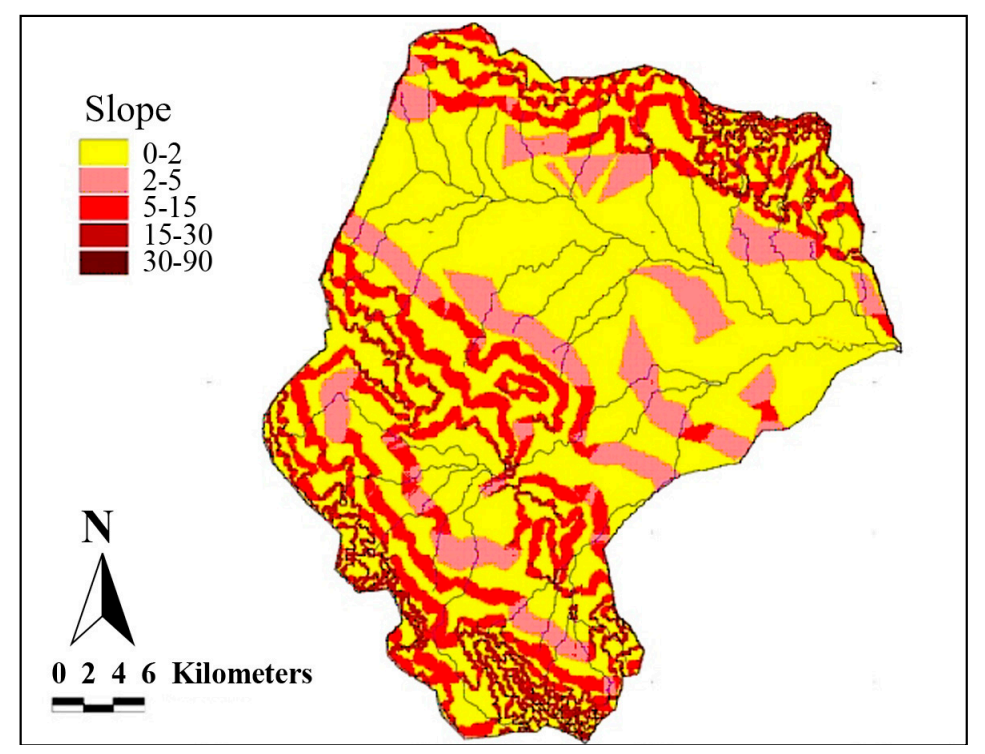

Figure 4. Slope map of the study area.

\subsubsection{Slope Aspect}

The slope aspect map of the Sangab basin has been presented in nine levels with the slope aspect identified within each area. According to Figure 5, flatlands covered the largest area of the Sangab Plain and the direction of the slopes was seen more in the east and northeast. The rest of slope aspects were equally proportioned within the contained area (Figure 5).

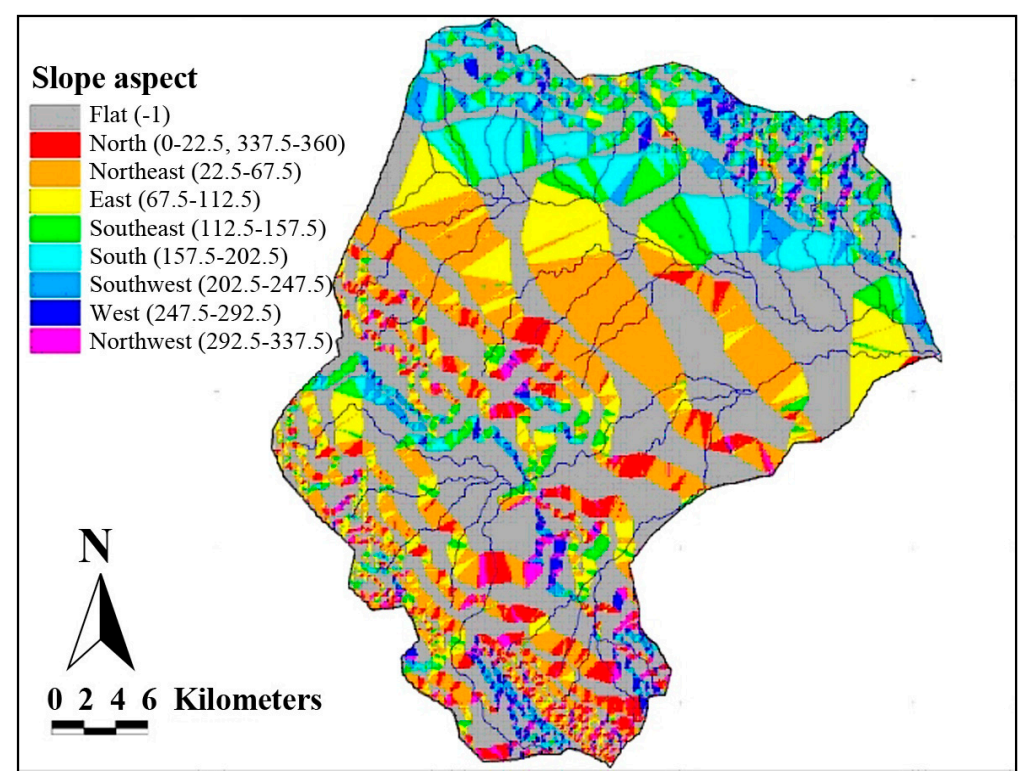

Figure 5. Aspect map of the study area. 


\subsubsection{Elevation}

Elevation affects agricultural land suitability due to its role in temperature changes, and the variations of plant cover. The vegetation and bloom periods are delayed by $4-6$ days for every additional $100 \mathrm{~m}$ in elevation on the mountains [14]. Figure 6 has eight levels, with a minimum and maximum distance between each level of $175 \mathrm{~m}$. The lowest level of elevation was 600-775 $\mathrm{m}$ and the highest level had an elevation of 1825-2000 m. Areas of low elevation are located in the east and the areas of the highest elevation are in the south.

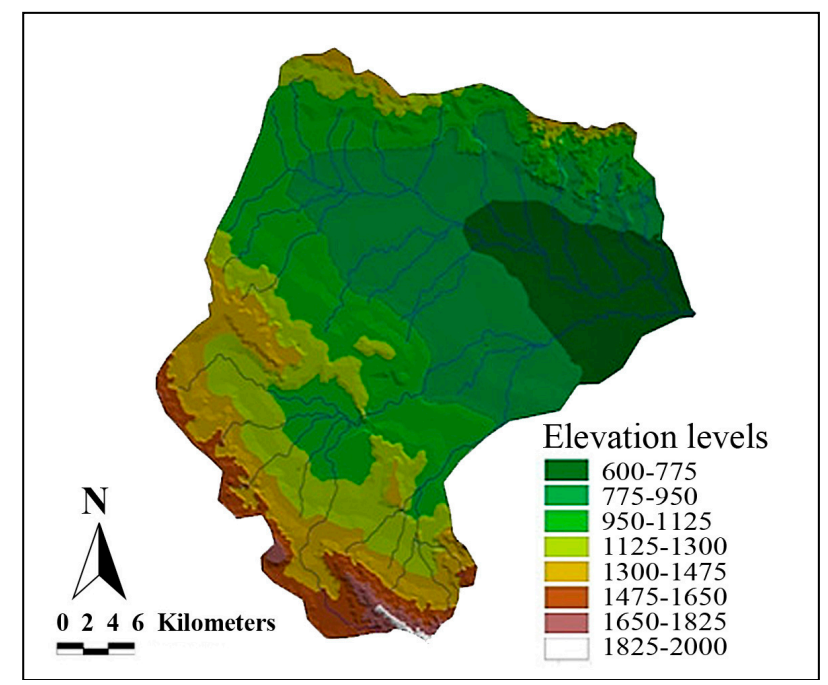

Figure 6. Elevation map of the study area.

\subsubsection{Soils}

The type of soil in an area of land is one of the most important factors of agricultural land suitability; soil behavior helps estimate the soil performance in agricultural production. Thus, when deciding on the suitability of land for agricultural production, it is necessary to know what types of soil are in the area. According to the topographical map, the soil resources map consists of four levels: mountain area, hill area, piedmont area, prairie and plains region. The soil map shows more mountain areas in the north, south, and southwest side; the center and east of this basin are devoted to mahoori hills, piedmont plains and flood plains (Figure 7).

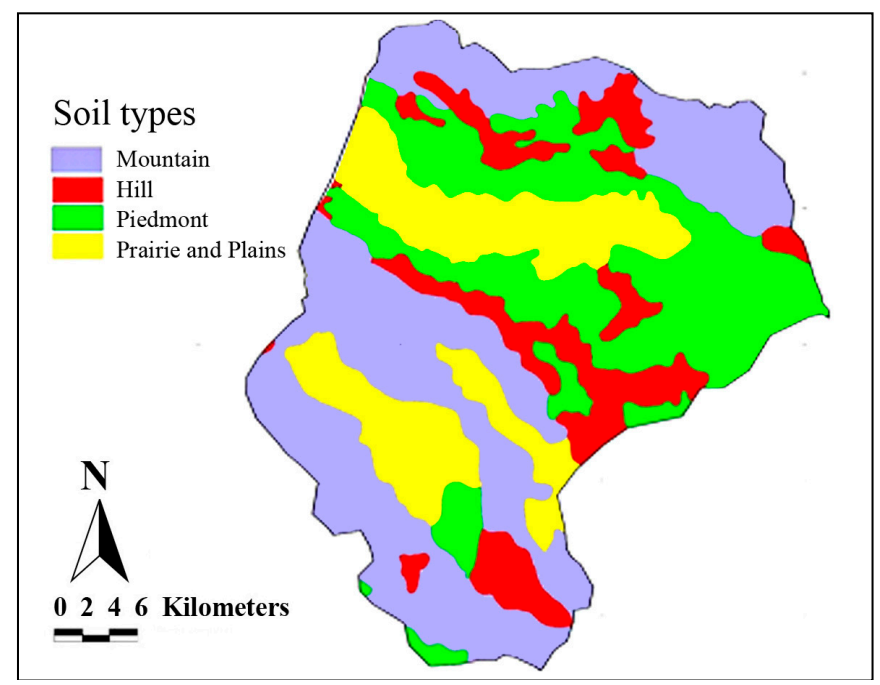

Figure 7. Soil map of the study area. 


\subsubsection{Land Use}

According to the topographical map (Figure 8), the land use map consists of four level; each level explains a type of land use. Based on this map, most of the space in the study area is devoted to rain-fed and grassland uses and with insignificant amounts of irrigated agronomy and no orchards.

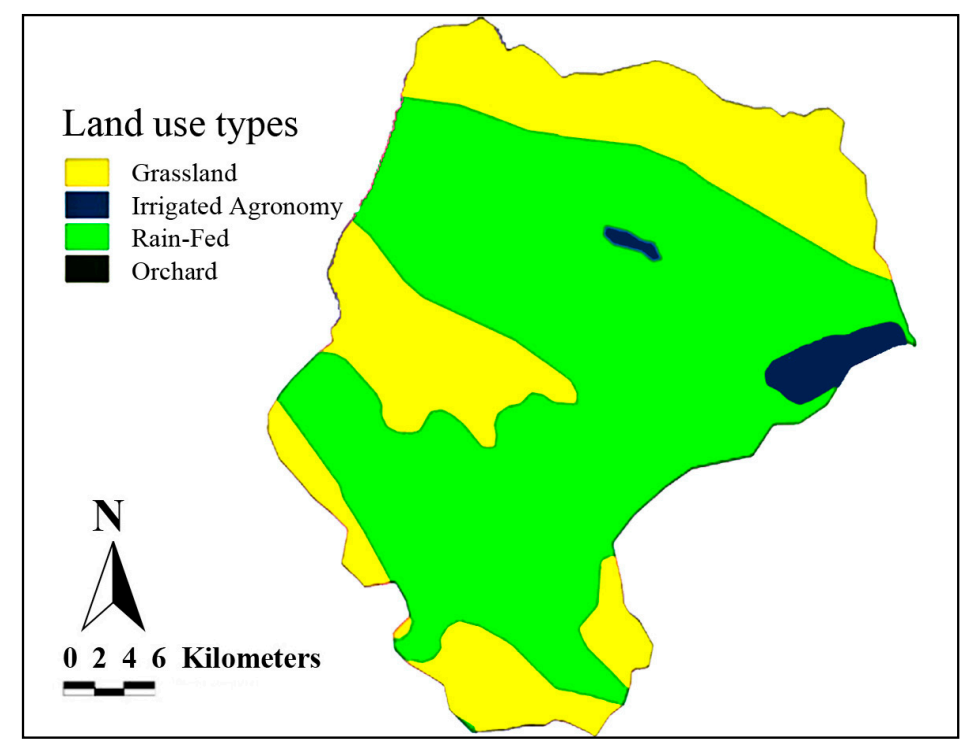

Figure 8. The map of the current land use in the study site.

\subsection{Ecological Model of Studied Area Potential Determination}

As mentioned in the methods section, to assess the situation and the potential of the environmental area and according to the characteristics of the study area, two models were generated to evaluate the suitability of the Sangab Plain (Tables 6 and 7). The suitability maps for grassland and agricultural land uses were prepared for each model after the ecological models were identified (Figures 9 and 10).

Table 6. Ecological model of agriculture use direction.

\begin{tabular}{ccccc}
\hline Current Use & Height $(\mathbf{m})$ & Soil & Slope (Degree) & Floor \\
\hline Rain-fed and Irrigated land & $600-950$ & Flood plain & $0-2$ & Lots \\
Rain-fed & $950-1125$ & Mahoori hill and piedmont plain & $2-5$ & Medium \\
Grassland & $1125-1825$ & Mountain regosols & $5-30$ & Inappropriate \\
\hline
\end{tabular}

Table 7. Ecological model of grassland use direction.

\begin{tabular}{ccccc}
\hline Current Use & Height $(\mathbf{m})$ & Soil & Slope (Degree) & Floor \\
\hline Grassland & $1475-1825$ & Mountain regosols & $15-30$ & Lots \\
Grassland & $950-1475$ & Mahoori hill and flood plain & $5-15$ & Medium \\
Rain-fed and Irrigated land & $600-950$ & Piedmont plain and flood plain & $0-5$ & Inappropriate \\
\hline
\end{tabular}




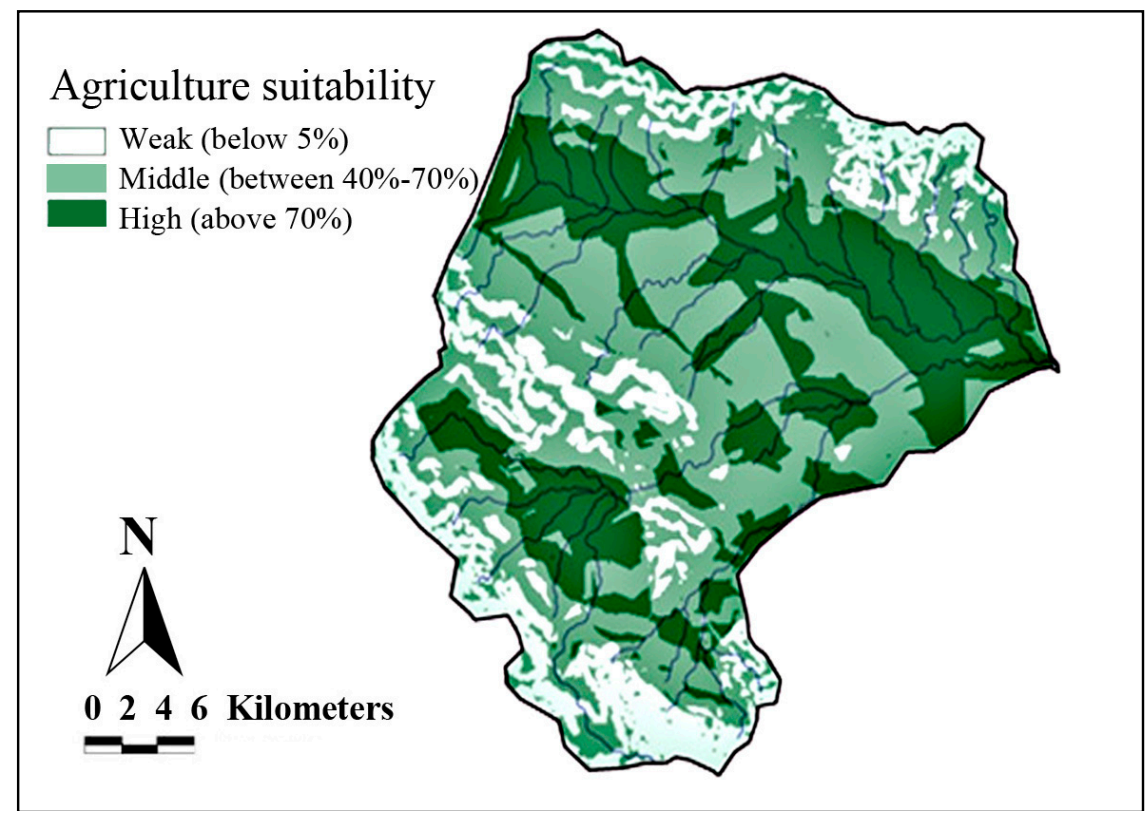

Figure 9. Agriculture suitability map of the Sangab plain.

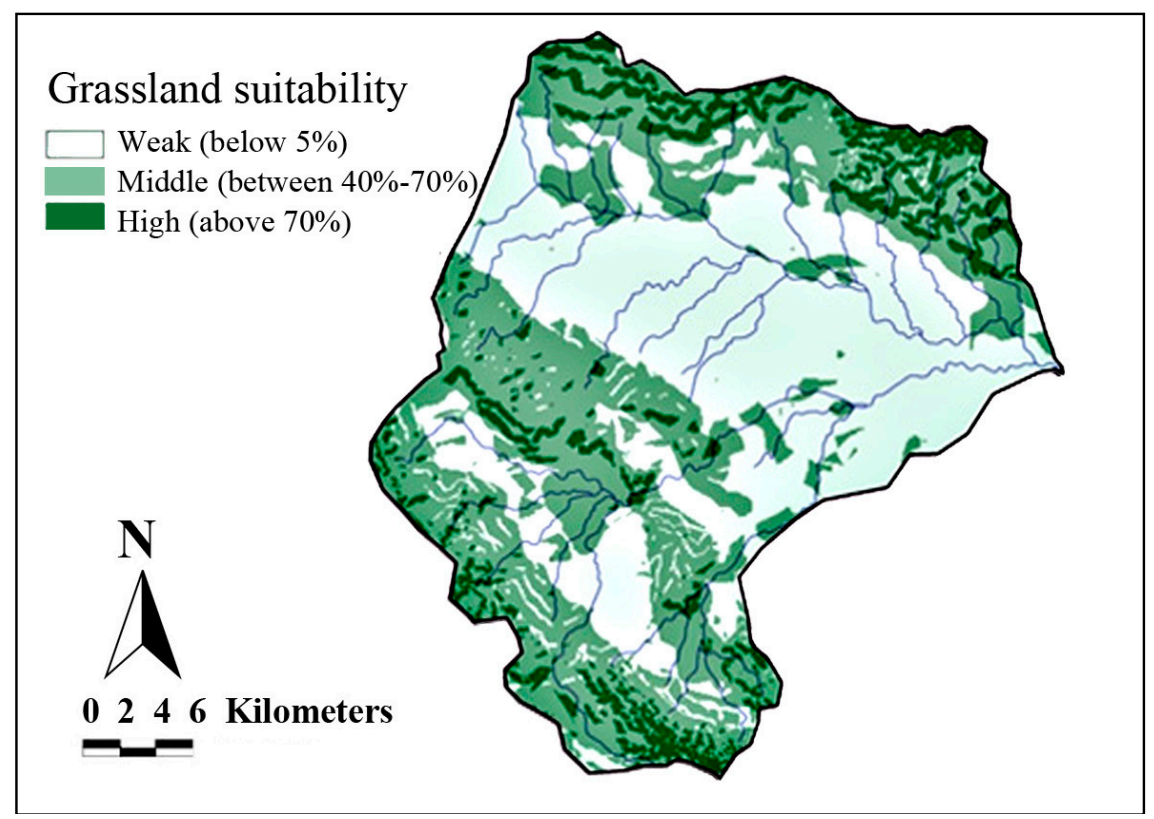

Figure 10. Grassland suitability map of the Sangab Plain.

The results from the evaluation of the Sangab Plain (agriculture and grassland suitability of the studied area) are shown in Figure 11. By using the outcomes of the indexes of weight determination and spatial basis studies, the ecological capability of the studied area was estimated for agriculture and grassland uses (Figures 9 and 10). From the total area of the studied lands, 20\% had high (rich), 65\% had medium (fair), and 15\% had low (poor) potential for "agriculture", whereas about 7\% showed high (rich), 23\% medium (fair), and 70\% had low (poor) potential for "grassland" use (Figure 10). It then seems that most of the land in the study area are more appropriate for agriculture or grassland. 


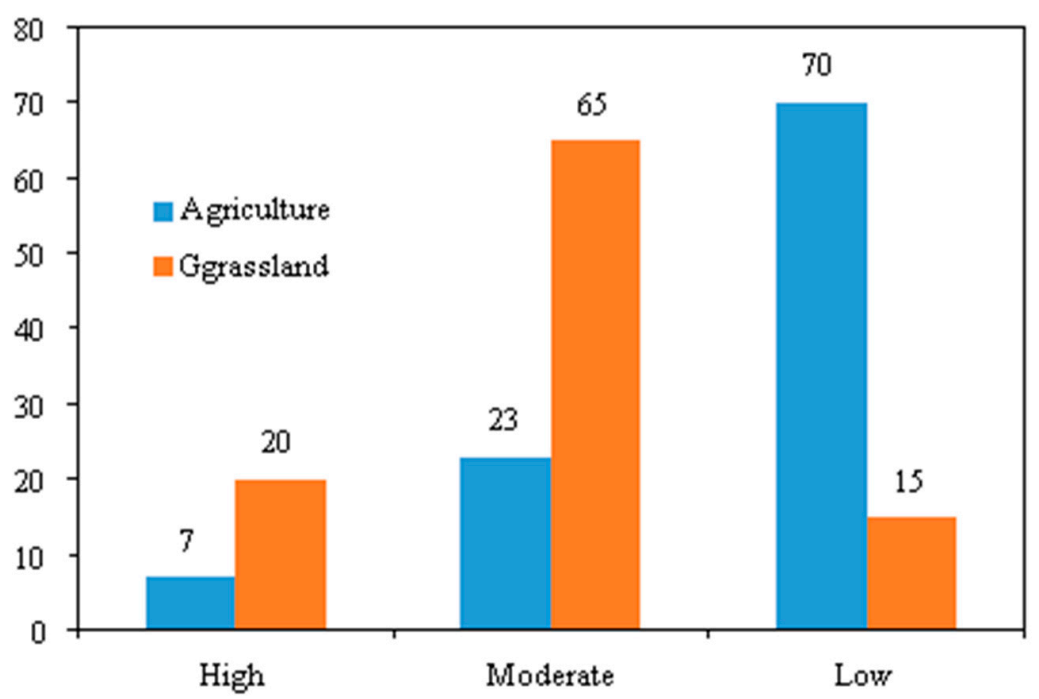

Figure 11. Percentage chart of agriculture and grassland suitability.

\section{Conclusions}

Determining the appropriate use of land to make the best use of the land in the country and to prevent depletion of resources due to population growth could and would be a useful way to devise strategies for stable expansion $[37,38]$. This study implemented an integrated GIS and AHP-based method to evaluate the suitability of agricultural land and grassland in the study area. The case study looked at physical, agronomic and socio-economic criteria. These criteria comprised 12 factors, including topography, soil, vegetation, water availability, soil fertility, rangeland grazing capacity, cropping pattern, supply market and revenue increase, and investment. Similar to Zhang et al. [8], Yalew, van Griensven, and van der Zaag [39], Romano et al. [40], Hamzeh et al. [41] and Jankowski [42], in this study, the AHP technique was used to calculated the weights of each factor.

The suitability map of agricultural land and grassland was generated by ArcMap. According to our study, the lands with (a) a slope from 0 to 2 degrees, (b) a flood soil type, and (c) an elevation from 600 to $950 \mathrm{~m}$ are the most suitable for agriculture. In addition, the study showed that the site in question is suitable for agriculture and is now being used for irrigated and rain-fed agronomy. It is, therefore, ecologically adaptive. In contrast, areas with (a) a slope from 15 to 30 degrees, (b) mountainous regosol soil, and (c) elevation floors from 1475 to $1825 \mathrm{~m}$, are suitable for use as grassland. Therefore, grassland use is also adaptive in terms of the area's ecological characteristics. Grasslands are also used to control the erosion of highly erodible lands [43,44]. Grasses are used in crop rotations and in strip cropping systems to slow surface water flow [45], to increase infiltration [46,47], and to reduce sediment running off tilled fields [48]. Despite this, it seems that the lands of study area were more suitable for agriculture than for grassland. Moreover, the results displayed that the socio-economic criteria are the least important criteria for investigating the suitability of land use. In other words, the suitability of any land for any use should be determined primarily on physical criteria, secondarily on agronomic criteria, and finally, on socio-economic criteria. However, various studies [49-58] have shown that socio-economic factors and variables have always played an important role in land use change. In that case, although socio-economic factors and variables may not have a direct and important role on determining the suitability of lands for agriculture or other uses, through their impacts on land use and cover changes they do affect it. At the same time, if the type of land use was suitable, future changes in land use are less likely [58-60].

Furthermore, in recent years farmers have been encouraged to convert cornfields into permanent grasslands, whenever soil and economic sustainability become questionable. The priority of land use in some of the units is determined by political needs, and there is no possibility of that changing [61]. 
In some units where one particular use does not have any advantage over the others and are close in terms of priority, multiple uses may be proposed [35].

Although GIS offers greater flexibility and accuracy in land use planning, some researchers [62-67] have emphasized that combining GIS with tools and methods, such as AHP, will produce better results. In this study, we combined AHP and GIS analyses; we used AHP to weigh the criteria and sub-criteria, as they do not have the same importance in their roles when determining the type of land uses. We also used GIS to survey the situation and the potential of the environmental area and the characteristics of the study area to evaluate the suitability of the lands. Our findings revealed that this combination could improve decision making for policy makers and planners. It can enable them to use more criteria with different weights when making a strategy, policy or decision about whether to preserve or change the use of a land area. It also could combine the experts' views in the process of decision making. Then, we argue that although those land use planners have conducted similar exercises in the past using manual methods, GIS can do the same much faster. Planners can use the present evaluation in their future agricultural and grassland expansions; utilizing information on the least suitable areas for development and practicing conservation is an important part of decision making. Because these combinations are difficult components of the decision-making process, planners will want to judge whether land should be developed or conserved. The combination of the AHP method with GIS is a new trend in land use planning and this study confirms that the findings of other researchers could be powerfully combined and applied in land use planning. This conclusion is consistent with the findings of Weerakoon [67], Duc [64], Al-Shalabi et al. [62], Chen et al. [63] and Thapa and Murayama [66].

Author Contributions: This study presents a team work developed by several authors. Elnaz Memarbashi wrote the main text. Hossein Azadi designed the structure of the paper and enriched the draft from the first to acceptable versions. Ali Akbar Barati and Fatemeh Mohajeri assisted the other authors in enriching the first draft to come up with the final draft. Steven Van Passel and Frank Witlox critically reviewed the paper and helped in addressing the reviewers' comments. With different contributions, all the authors enriched the submitted manuscript and ended it up with the current publication.

Conflicts of Interest: The authors declare no conflict of interest.

\section{References}

1. Bhagat, V.S. Use of remote sensing techniques for robust digital change detection of land: A review. Recent Pat. Space Technol. 2012, 2, 123-144. [CrossRef]

2. Zolekar, R.B.; Bhagat, V. Use of IRS P6 LISS-IV data for land suitability analysis for cashew plantation in hilly zone. Asian J. Geoinform. 2014, 14, 23-35.

3. Zolekar, R.B.; Bhagat, V.S. Multi-criteria land suitability analysis for agriculture in hilly zone: Remote sensing and GIS approach. Comput. Electron. Agric. 2015, 118, 300-321. [CrossRef]

4. Sivakumar, M.V.K.; Ndiang'ui, N. Climate and Land Degradation; Springer: Berlin/Heidelberg, Germany, 2007.

5. Food and Agriculture Organization of the United Nations (FAO); World Food Programme (WFP); International Fund for Agricultural Development (IFAD). The State of Food Insecurity in the World 2012: Economic Growth Is Necessary but Not Sufficient to Accelerate Reduction of Hunger and Malnutrition; FAO: Rome, Italy, 2012; Volume 10.

6. Nwer, B.A.B. The Application of Land Evaluation Technique in the North-East of Libya. Ph.D. Thesis, University of Tripoli, Tripoli, Libya, January 2006.

7. Joerin, F.; Thériault, M.; Musy, A. Using GIS and outranking multicriteria analysis for land-use suitability assessment. Int. J. Geogr. Inf. Sci. 2001, 15, 153-174. [CrossRef]

8. Zhang, J.; Su, Y.; Wu, J.; Liang, H. GIS based land suitability assessment for tobacco production using AHP and fuzzy set in Shandong province of China. Comput. Electron. Agric. 2015, 114, 202-211. [CrossRef]

9. Elsheikh, R.; Shariff, A.R.B.M.; Amiri, F.; Ahmad, N.B.; Balasundram, S.K.; Soom, M.A.M. Agriculture Land Suitability Evaluator (ALSE): A decision and planning support tool for tropical and subtropical crops. Comput. Electron. Agric. 2013, 93, 98-110. [CrossRef]

10. Marinoni, O. A discussion on the computational limitations of outranking methods for land-use suitability assessment. Int. J. Geogr. Inf. Sci. 2006, 20, 69-87. [CrossRef] 
11. McHarg, I.L.; Mumford, L. Design with Nature; American Museum of Natural History: New York, NY, USA, 1969.

12. Bronsveld, K.; Huizing, H.; Omakup, M. Improving land evaluation and land use planning. ITC J. 1994, 4, 359-365.

13. Rossiter, D.G. A theoretical framework for land evaluation. Geoderma 1996, 72, 165-190. [CrossRef]

14. Bozdă̆, A.; Yavuz, F.; Günay, A.S. AHP and GIS based land suitability analysis for Cihanbeyli (Turkey) County. Environ. Earth Sci. 2016, 75, 1-15. [CrossRef]

15. Saaty, T.L. The Analytic Hierarchy Process; McGraw-Hill International: New York, NY, USA, 1980.

16. Aragonés-Beltrán, P.; Chaparro-González, F.; Pastor-Ferrando, J.-P.; Pla-Rubio, A. An AHP (Analytic Hierarchy Process) / ANP (Analytic Network Process)-based multi-criteria decision approach for the selection of solar-thermal power plant investment projects. Energy 2014, 66, 222-238. [CrossRef]

17. Herrero, M.; Fawcett, R.; Dent, J. Bio-economic evaluation of dairy farm management scenarios using integrated simulation and multiple-criteria models. Agric. Syst. 1999, 62, 169-188. [CrossRef]

18. Jaafari, A.; Najafi, A.; Melón, M.G. Decision-making for the selection of a best wood extraction method: An analytic network process approach. For. Policy Econ. 2015, 50, 200-209. [CrossRef]

19. Mazzetto, F.; Bonera, R. MEACROS: A tool for multi-criteria evaluation of alternative cropping systems. Eur. J. Agron. 2003, 18, 379-387. [CrossRef]

20. Rozman, Č.; Pazek, K.; Bavec, F.; Bavec, M.; Turk, J.; Majkovič, D. A multi-criteria analysis of spelt food processing alternatives on small organic farms. J. Sustain. Agric. 2006, 28, 159-179. [CrossRef]

21. Tiwari, D.; Loof, R.; Paudyal, G. Environmental-economic decision-making in lowland irrigated agriculture using multi-criteria analysis techniques. Agric. Syst. 1999, 60, 99-112. [CrossRef]

22. Rossiter, D. Economic land evaluation: Why and how. Soil Use Manag. 1995, 11, 132-140. [CrossRef]

23. Van de Putte, R. Land evaluation and project planning. ITC J. 1989, 2, 139-143.

24. Gemitzi, A.; Tsihrintzis, V.A.; Petalas, C. Use of GIS and multi-criteria evaluation techniques in environmental problems. Multimed. Serv. Intell. Environ. 2010, 3, 5-62.

25. Krois, J.; Schulte, A. GIS-based multi-criteria evaluation to identify potential sites for soil and water conservation techniques in the Ronquillo watershed, northern Peru. Appl. Geogr. 2014, 51, 131-142. [CrossRef]

26. Al-Adamat, R.; Diabat, A.; Shatnawi, G. Combining GIS with multicriteria decision making for siting water harvesting ponds in Northern Jordan. J. Arid Environ. 2010, 74, 1471-1477. [CrossRef]

27. Ekmekçioĝlu, M.; Kaya, T.; Kahraman, C. Fuzzy multicriteria disposal method and site selection for municipal solid waste. Waste Manag. 2010, 30, 1729-1736. [CrossRef] [PubMed]

28. Baiocchi, V.; Lelo, K.; Polettini, A.; Pomi, R. Land suitability for waste disposal in metropolitan areas. Waste Manag. Res. 2014, 32, 707-716. [CrossRef] [PubMed]

29. Tavares, G.; Zsigraiová, Z.; Semiao, V. Multi-criteria GIS-based siting of an incineration plant for municipal solid waste. Waste Manag. 2011, 31, 1960-1972. [CrossRef] [PubMed]

30. Moeinaddini, M.; Khorasani, N.; Danehkar, A.; Darvishsefat, A.A. Siting MSW landfill using weighted linear combination and analytical hierarchy process (AHP) methodology in GIS environment (case study: Karaj). Waste Manag. 2010, 30, 912-920. [CrossRef] [PubMed]

31. Patil, V.; Sankhua, R.; Jain, R. Analytic hierarchy process for evaluation of environmental factors for residential land use suitability. Int. J. Comput. Eng. Res. 2012, 2, 182-189.

32. Ambarwulan, W.; Setiawan, Y.; Walter, C. Assessing the Suitability and Availability of Land for Agriculture in Tuban Regency, East Java, Indonesia. Appl. Environ. Soil Sci. 2016, 13. [CrossRef]

33. Kiker, G.A.; Bridges, T.S.; Varghese, A.; Seager, T.P.; Linkov, I. Application of multicriteria decision analysis in environmental decision making. Integr. Environ. Assess. Manag. 2005, 1, 95-108. [CrossRef] [PubMed]

34. Vlek, P.L.G.; Azadi, H.; Bhaduri, A.; Bharati, L.; Braimoh, A.K.; Martius, C.; Sunderland, T.; Taheri, F. The trade offs in multi-purpose land use. In Land Degradation and the Sustainable Development Goals: Threats and Potential Remedies; Vlek, P., Tamane, L., Eds.; International Centre for Tropical Agriculture (CIAT): Nairobi, Kenya, 2017; pp. 5-17.

35. Makhdoom, M. Fundamental of Land Use Planning; Tehran University Press: Tehran, Iran, 2001.

36. Koulouri, M.; Giourga, C. Land abandonment and slope gradient as key factors of soil erosion in Mediterranean terraced lands. Catena 2007, 69, 274-281. [CrossRef]

37. Bocco, G.; Mendoza, M.; Velázquez, A. Remote sensing and GIS-based regional geomorphological mapping-A tool for land use planning in developing countries. Geomorphology 2001, 39, 211-219. [CrossRef]

38. Prato, T. Evaluating land use plans under uncertainty. Land Use Policy 2007, 24, 165-174. [CrossRef] 
39. Yalew, S.G.; van Griensven, A.; van der Zaag, P. AgriSuit: A web-based GIS-MCDA framework for agricultural land suitability assessment. Comput. Electron. Agric. 2016, 128, 1-8. [CrossRef]

40. Romano, G.; Dal Sasso, P.; Trisorio Liuzzi, G.; Gentile, F. Multi-criteria decision analysis for land suitability mapping in a rural area of Southern Italy. Land Use Policy 2015, 48, 131-143. [CrossRef]

41. Hamzeh, S.; Mokarram, M.; Alavipanah, S.K. Combination of Fuzzy and AHP methods to assess land suitability for barley: Case Study of semi arid lands in the southwest of Iran. Desert 2014, 19, 173-181.

42. Jankowski, P. Integrating geographical information systems and multiple criteria decision-making methods. Int. J. Geogr. Inf. Syst. 1995, 9, 251-273. [CrossRef]

43. Mangun, W.R.; Henning, D.H. Managing the Environmental Crisis: Incorporating Competing Values in Natural Resource Administration; Duke University Press: Durham, NC, USA, 1999.

44. Robinson, R.A. Conservation Security Program: Despite Cost Controls, Improved USA Management Is Needed to Ensure Proper Payments and Reduce Duplication with Other Programs; DIANE Publishing Company: Collingdale, PA, USA, 2006.

45. Hussein, J.; Yu, B.; Ghadiri, H.; Rose, C. Prediction of surface flow hydrology and sediment retention upslope of a vetiver buffer strip. J. Hydrol. 2007, 338, 261-272. [CrossRef]

46. Adekalu, K.; Olorunfemi, I.; Osunbitan, J. Grass mulching effect on infiltration, surface runoff and soil loss of three agricultural soils in Nigeria. Bioresour. Technol. 2007, 98, 912-917. [CrossRef] [PubMed]

47. Novotná, J.; Badalíková, B. The Influence of Grass Species Composition on Fishpond Dikes on Soil Infiltration. Acta Univ. Agric. Silvic. Mendel. Brun. 2016, 64, 1619-1623. [CrossRef]

48. Natural Resources Conservation Service (NRCS); US Department of Agriculture (USDA). National Handbook of Conservation Practices; US Department of Agriculture/Natural Resources Conservation Service: Washington, DC, USA, 1999.

49. Agricultural Bank. The Condition of Agricultural Lands Use Changes; Agricultural Bank: Tehran, Iran, 2011.

50. Asadi, A.; Barati, A.; Kalantari, K.; Odeh, I. Study of Relationship Between Roads Network Development and Agricultural Land Conversion in Iran NorthWest. Int J. Environ. Res. 2016, 10, 51-58.

51. Barati, A.A.; Asadi, A.; Kalantari, K.; Azadi, H.; Mamoorian, M. Analyzing the impacts of agricultural land use change according to the experts opinion of agricultural land organization in Iran. Iran. J. Agric. Econ. Dev. Res. 2015, 45, 639-650.

52. Barati, A.A.; Asadi, A.; Kalantari, K.; Azadi, H.; Witlox, F. Agricultural Land Conversion in Northwest Iran. Int. J. Environ. Res. 2015, 9, 281-290.

53. Azadi, H.; Barati, A.A.; Rafiaani, P.; Raufirad, V.; Zarafshani, K.; Mamoorian, M.; Lebailly, P. Agricultural Land Conversion Drivers in Northeast Iran: Application of Structural Equation Model. Appl. Spat. Anal. Policy 2016, 9, 591-609. [CrossRef]

54. Azadi, H.; Barati, A.A.; Rafiaani, P.; Taheri, F.; Gebrehiwot, K.; Witlox, F.; Lebailly, P. Evolution of land use-change modeling: Routes of different schools of knowledge. Landsc. Ecol. Eng. 2016, 13, 1-14. [CrossRef]

55. Olaniyi, A.O.; Abdullah, A.M.; Ramli, M.F.; Alias, M.S. Assessment of drivers of coastal land use change in Malaysia. Ocean Coast. Manag. 2012, 67, 113-123. [CrossRef]

56. Rótolo, G.C.; Montico, S.; Francis, C.A.; Ulgiati, S. How land allocation and technology innovation affect the sustainability of agriculture in Argentina Pampas: An expanded life cycle analysis. Agric. Syst. 2015, 141, 79-93. [CrossRef]

57. Wang, J.; Chen, Y.; Shao, X.; Zhang, Y.; Cao, Y. Land-use changes and policy dimension driving forces in China: Present, trend and future. Land Use Policy 2012, 29, 737-749. [CrossRef]

58. Zarkesh, M.M.K.; Ghoddusi, J.; Zaredar, N.; Soltani, M.J.; Jafari, S.; Ghadirpour, A. Application of spatial analytical hierarchy process model in land use planning. J. Food Agric. Environ. 2010, 8, 970-975.

59. Bin, Q.; He-Jian, Z.; Song-Lin, C.; RÖmkens, M.; Bi-Cheng, L. Land Suitability Assessment and Land Use Change in Fujian Province, China** Project supported by the Provincial Natural Science Foundation of Fujian, China (No. D0210010). Pedosphere 2007, 17, 493-504.

60. Roberts, M.C.; Randolph, J.C.; Chiesa, J.R. A land suitability model for the evaluation of land-use change. Environ. Manag. 1979, 3, 339-352. [CrossRef]

61. Pierce, S.M.; Cowling, R.M.; Knight, A.T.; Lombard, A.T.; Rouget, M.; Wolf, T. Systematic conservation planning products for land-use planning: Interpretation for implementation. Biol. Conserv. 2005, 125, 441-458. [CrossRef] 
62. Al-Shalabi, M.A.; Mansor, S.B.; Ahmed, N.B.; Shiriff, R. GIS Based Multicriteria Approaches to Housing Site Suitability Assessment. Presented at the XXIII FIG Congress, Shaping the Change, Munich, Germany, 8-13 October 2006.

63. Chen, Y.; Khan, S.; Padar, Z. Irrigation intensification or extensification assessment: A GIS-based spatial fuzzy multi-criteria evaluation. In Proceedings of the 8th International Symposium on Spatial Accuracy Assessment in Natural Resources and Environmental Sciences, Shanghai, China, 25-27 June 2008.

64. Duc, T.T. Using GIS and AHP technique for land-use suitability analysis. Presented at the International Symposium on Geoinformatics for Spatial infrastructure Development in Earth and Allied Sciences, Ho Chi Minh City, Vietnam, 9-11 November 2006.

65. Javaheri, H.; Nasrabadi, T.; Jafarian, M.; Rowshan, G.; Khoshnam, H. Site selection of municipal solid waste landfills using analytical hierarchy process method in a geographical information technology environment in Giroft. J. Environ. Health Sci. Eng. 2006, 3, 177-184.

66. Thapa, R.B.; Murayama, Y. Land evaluation for peri-urban agriculture using analytical hierarchical process and geographic information system techniques: A case study of Hanoi. Land Use Policy 2008, 25, 225-239. [CrossRef]

67. Weerakoon, K. Integration of GIS based suitability analysis and multicriteria evaluation for urban land use planning; contribution from the Analytic Hierarchy Process. Presented at the 23rd Asian Conference on Remote Sensing, ACRS Urban Planning, Kathmandu, Nepal, 25-29 November 2002.

(C) 2017 by the authors. Licensee MDPI, Basel, Switzerland. This article is an open access article distributed under the terms and conditions of the Creative Commons Attribution (CC BY) license (http://creativecommons.org/licenses/by/4.0/). 